\title{
A percepção do corpo em pacientes bariátricos e a experiência do medo do reganho do peso
}

Simone Dallegrave Marchesini

Maria Cristina Antunes

\section{RESUMO}

O presente artigo analisou alterações na percepção corporal e medo do reganho de peso em 10 pacientes submetidos à cirurgia bariátrica de Fobi-Capella (Bypass Gástrico em Y de Roux) há no mínimo quatro anos, que tiveram reganho de pelo menos $20 \%$ do peso perdido. Foi utilizado um roteiro de entrevista semiestruturada sobre: dados demográficos, hábitos alimentares, mudanças no estilo de vida e comportamentais, imagem corporal, preconceitos vivenciados e reaquisição de peso. As entrevistas foram gravadas, transcritas e submetidas à análise de conteúdo. Observou-se que o reganho de peso ocorreu de modo desapercebido pelo paciente, até que tenha sido sinalizado socialmente; o emagrecimento excessivo foi mal avaliado pelos pares; observou-se medo acentuado, por parte dos operados bariátricos, de voltar à obesidade mórbida; os participantes relataram alterações nas relações afetivas; a percepção da imagem corporal oscilou e era infiel à aparência externa.

Palavras-chaves: reganho de peso; imagem corporal; cirurgia bariátrica.

\section{ABSTRACT}

\section{Body perception and fear of weight regain in bariatric pacients}

The present paper aims to discuss the perception of body image and the fear of weight regain in 10 patients who underwent Fobi-Capella bariatric surgery (Roux in Y gastric bypass), at least four years ago, and have regained $15 \%$ or more of the total loss of body weight. Semi structured interviews were applied and included questions about demographics data, dietary habits, lifestyle changes, behavioral changes, body image, prejudice experiences and weight regain. The recorded interviews had their content analyzed and transcribed. Results demonstrated that weight regain occurs unnoticed by the patient, until it has been signaled socially; the excessive weight loss didn't get approval by peers; the fear to return to morbid obesity was noticed; the changes on personal relationships were clear and there were oscillations in the reconstruction of body image with a poor and inconsistent new self-image.

Keywords: weight regain, body image, bariatric surgery.

Segundo dados do relatório da Organização das Nações Unidas para Alimentação e Agricultura (FAO) e da Organização Pan-Americana de Saúde (OPAS), no documento "Panorama da Segurança Alimentar e Nutricional na América Latina e Caribe", mais de 50\% dos brasileiros estão com sobrepeso e a obesidade atinge $20 \%$ das pessoas adultas (Organização das Nações Unidas no Brasil - ONUBR, 2017). O surgimento de diferentes técnicas em cirurgia bariátrica vem colaborando para a remissão em longo prazo de doenças sérias e epidêmicas como o Diabetes.

De acordo com a Sociedade Brasileira de Cirurgia Bariátrica e Metabólica (SBCBM, 2017), em dezembro de 2006 firmou-se no Brasil a obrigatoriedade da presença da "equipe multidisciplinar habilitada em programas de cirurgias bariátricas para o atendimento do paciente obeso mórbido e os critérios para a realização das cirurgias bariátricas". Esses critérios se

\section{Sobre os Autores}

S.D.M.

orcid.org/0000-0002-6767-518X Universidade Tuiuti do Paraná (UTP) - Curitiba, PR simonedallmarc@yahoo.com

M.C.A.

orcid.org/0000-0002-7983-7174 Universidade Tuiuti do Paraná (UTP) - Curitiba, PR mcrisantunes@uol.com.br

\section{Direitos Autorais}

Este é um artigo de acesso aberto e pode ser reproduzido livremente, distribuído, transmitido ou modificado, por qualquer pessoa desde que usado sem fins comerciais. $O$ trabalho é disponibilizado sob a licença Creative Commons CCBY-NC.

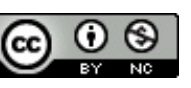




\section{H NTERAC̄OA EM EST PSICOLOGIA}

atualizaram e hoje a realização da cirurgia pode ser feita nos seguintes casos: em pessoas com índice de massa corporal IMC $40 \mathrm{~kg} / \mathrm{m} 2$; em pessoas com IMC $35 \mathrm{~kg} / \mathrm{m} 2$, desde que haja uma ou mais doenças já manifestas que justifiquem a emergência da operação. Quanto à idade: no limite inferior de 16 anos, devido a problemas metabólicos e psíquicos do adolescente obeso; no limite superior de 65 em condições de vida particulares da pessoa da terceira idade. A depressão, por ser considerada uma das doenças consequências da obesidade, enquanto estado inflamatório do cérebro, passou a ser considerada critério para realização da cirurgia bariátrica.

Mitchel et al (2001), em artigo recente sobre cuidados psiquiátricos do paciente bariátrico, ressaltou que o sucesso da cirurgia não depende apenas do procedimento médico realizado, mas também de mudanças globais no estilo de vida como exercícios físicos, mudanças na alimentação e manejo das alterações psicossociais vividas. Faln (2012) em entrevista com David Sarwer sobre a correlação entre a imagem corporal e a perda de peso, disse que não há garantias que o caminho da diminuição numérica na balança seja a receita certa para o aumento da autoestima. 0 autor observou que mesmo pacientes bariátricos que perdem grande quantidade de peso, permanecem com insatisfações relacionadas à imagem corporal. De três a seis meses após a cirurgia, há grande satisfação com os resultados dela, mas acarreta em outro problema que é a sobra de pele após o rápido emagrecimento, que, segundo o autor, provavelmente está relacionado com o fato de que cerca de 50.000 americanos anualmente realizam cirurgia plástica corretiva e estética. Estudos demonstram que existe progressão do reganho de peso à medida em que decorre o tempo de cirurgia (Karmali et al, 2013). Em um estudo com público brasileiro (Magro, 2006), 60\% dos pacientes tem reganho de $8,8 \mathrm{~kg}$ em um período de 5 anos de pósoperatório em cirurgia de by-pass gástrico com derivação em Y-de Roux (ou Fobi Capella).

Com relação à construção social da imagem corporal e da beleza, observa-se que as mulheres ficam menos satisfeitas com seus próprios corpos quanto mais são expostas às modelos consideradas perfeitas pela mídia. $E$ também se observa que os homens as julgam mais como pouco atraentes. Esses modelos estéticos também criam insatisfações nos relacionamentos afetivos. Aspectos relacionados à mídia, aparência, insatisfação corporal, pouca autoestima, transtornos alimentares, depressão e ansiedade estão intimamente relacionados (Cash, Cash, \& Butters, 1983; Stice, Schupak-Neuberg, Shaw \& Stein, 1994; Souza, Oliveira, Nascimento, \& Carvalho, 2013).

As revistas pesquisadas reproduzem imagens estereotipadas sobre a mulher e seu corpo, limitam sua importância e utilidade social às funções de baixo reconhecimento, restritas ao ambiente familiar e à prática sexual. Em contrapartida, as singularidades e a potencialidade intelectual das mulheres são desprezadas, levando as pessoas a adotarem conceitos que as igualam nestas funções e alimentam a existência de uma necessária sujeição feminina e uma suposta superioridade masculina. (Souza et al., 2013, p. 68)

Agliata e Tantleff-Dunn (2004) constataram que mulheres sofrem maior influência da opinião de seu grupo sobre a estruturação da imagem ideal do corpo que os homens. Para os homens, as personalidades de fama e sucesso são referenciais do ideal. 0 agravamento da influência midiática sobre a imagem corporal ocorre, no entanto, quando meios de comunicação exibem imagens artificiais como se fossem reais e afastam em demasia o possível do impossível, o que faz aumentar o grau de insatisfação corporal e resulta em elevado índice de distúrbios da alimentação.

A imagem corporal envolve a autopercepção do corpo e a autopercepção das atitudes relacionadas ao próprio corpo. Esse conjunto abarca pensamentos, crenças, sentimentos e comportamentos direcionados ao eu corporal (Cash, 2003). 0 termo imagem corporal vem sendo usado para se referir à imagem mental que uma pessoa faz de seu "eu físico", uma avaliação da própria aparência e a influência que esses fatores exercem sobre o próprio comportamento. 0 distúrbio da imagem corporal tem sido estudado no intuido de conhecer sua influência e sua correlação com a personalidade e a quadros psicopatológicos (Rosen, 1990).

Rosen e James (2001) estudou a imagem corporal em pessoas obesas e verificou que é inegável a insatisfação existente neste grupo, que aparece como fator motivacional para o indivíduo com peso excessivo nas tentativas frequentes de redução de peso, mas ao mesmo tempo é causa de insatisfação com o corpo, sofrimento e prejuízo psicossocial. Os autores afirmam 0 autor afirma que é possível intervir na mudança de atitudes e comportamentos de pessoas obesas por meio de uma abordagem estritamente psicológica, sem qualquer intervenção restritiva direta sobre a alimentação. 0 autor propõe um método psicoterápico, terapia da imagem corporal e obteve resultados positivos a curto prazo, mas afirma que a longo prazo não foram feitos estudos para comprovar sua eficácia.

Segundo Orzech (2005), em uma sociedade focada no corpo magro e esculturalmente construído, pessoas obesas e severamente obesas são deixadas à margem. Esses indivíduos sofrem discriminações tanto em ambientes escolares quanto no mercado de trabalho e têm prejuízo em sua vida pessoal e relacionamentos interpessoais. A cirurgia tem sido um meio para diminuir o processo de estigmatização e também resolver problemas de saúde que decorrem da obesida- 


\section{H NTERAC̄OA EM ET PSICOLOGIA}

de e que diminuem a qualidade de vida.

0 tratamento cirúrgico da obesidade deixa ao paciente diversas tarefas e responsabilidades sobre a manutenção dos resultados obtidos. Antes do emagrecimento em grande escala, provocado pelo tratamento cirúrgico, o paciente tem crenças sobre seu corpo e sua forma física e sobre como as pessoas o percebem (Orzech, 2005). Após o procedimento é comum que ocorram dificuldades nas mudanças de suas concepções já "enraizadas". Os registros das crenças antigas precisam ser confrontados e acomodados junto às novas experiências e à própria forma corporal. A concepção que o paciente submetido à cirurgia bariátrica passa a ter de si próprio e de seu valor pessoal tendem a se alterar e ocorre divórcio após a cirurgia bariátrica em larga escala. 0 fato de a pessoa ter sido obesa no momento do casamento ou quando o relacionamento iniciou, estabelece um risco de ruptura do vínculo matrimonial em 80 a $85 \%$ dentro de um período de dois anos após a cirurgia. A autoestima do operado e sua atratividade física exercem ameaças sobre o parceiro, antes acomodado com a garantia de poder implícito na relação. 0 reconhecimento dessa dinâmica velada na relação, considerada abusiva por Ozerch (2005), passa a não ser mais tolerada pelo indivíduo operado.

Mulheres obesas costumam ser ignoradas socialmente e muitas vezes esse é o propósito de tamanho acúmulo de gordura. Ao se tornarem mais magras, após o procedimento bariátrico, passam a ficar vulneráveis a olhares e cortejos. Nessas situações, a ajuda de um psicólogo é recomendada. A atenção e os elogios são frequentes em uma sociedade que valoriza a imagem física e o corpo. Para aqueles que foram obesos desde sempre, a experiência do flerte e da iniciação do cortejo é nova e a imagem atraente é acompanhada de ingenuidade e medo (Thompson, 2001).

Quanto à cirurgia plástica após cirurgia bariátrica, Steffen et al. (2012) fizeram um estudo sobre a procura e a satisfação da técnica da cirurgia plástica do contorno corporal. Foi utilizado um questionário de aparência física após a cirurgia bariátrica, no qual os participantes expressaram insatisfação com o excesso de pele na circunferência abdominal e regiões da coxa. A maior procura pela cirurgia plástica foi pela região da barriga e cintura e o nível de satisfação com a cirurgia do contorno corporal foi grande. O IMC (índice de massa corporal) não interferiu sobre a satisfação dos resultados, mas o tempo de cirurgia bariátrica interferiu sobre a motivação de se submeter a cirurgias corretivas. Os autores destacaram a importância de incluir já no preparo psicológico pré-operatório informações explícitas sobre a necessidade de cirurgias plásticas corretivas, para que as expectativas possam ser mais realistas.

McNally (2008) afirma que muitas pessoas descrevem seu processo após o tratamento cirúrgico da obesidade como uma "montanha russa", uma vez que há muita variação hormonal lipossolúvel. Muitas emoções positivas são vividas, ao mesmo tempo em que experiências em relação ao novo corpo também aparecem. Ressalta que o estado elevado de humor existe na maior parte do tempo, mas para algumas pessoas diminuir o peso não é o suficiente. Existem outros fatores, tais como aceitação, melhoria da imagem corporal e aumento da autoestima, que dependem das vivências sociais e psíquicas de cada um e necessitam de um longo trabalho psicológico.

Colles, Dixon e O'Brien (2008) se referiram aos gatilhos emocionais e situações que desencadeiam o desejo de comer após a cirurgia bariátrica. Perceberam que medo intenso de readquirir peso e percepção do retorno de velhos hábitos alimentares são os fatores que retroalimentam o desejo de comer. Observa-se que as pessoas que tinham um desejo intenso de comer perante diversos gatilhos emocionais foram aqueles que continuaram comendo, mesmo que estivessem se sentindo "cheios" e satisfeitos, apesar do medo de recuperar o peso. Ou seja, o medo de recuperar peso é também um desses gatilhos, que colaboram para o reganho de peso. Desta forma, é fundamental estudar a relação entre a imagem corporal e o medo do reganho de peso, por serem fatores importantes que desencadeiam o processo de comer em excesso, de forma a traçar estratégias de prevenção e intervenção, antes e após a cirurgia bariátrica.

Desta forma, o presente artigo analisou as alterações na percepção corporal e medo do reganho de peso em pacientes submetidos à cirurgia bariátrica de Fobi-Capella que tiveram reganho do peso perdido.

\section{MÉTODO}

\section{PARTICIPANTES}

Para a realização do presente estudo foram incialmente contatados 30 pacientes, via telefone, com base em uma lista de operados de uma clínica particular em Curitiba. 0 critério inicial era que os pacientes tivessem se submetido à técnica cirúrgica de by-pass gástrico com derivação em Y-de-Roux e estivessem apresentando reganho de peso. Desses pacientes, 16 se dispuseram a ser entrevistados. Apenas 10 foram selecionados por preencherem os critérios de aumento de pelo menos $20 \%$ do peso perdido, critério utilizado para definir reganho de peso (Berti et al., 2015) há no mínimo quatro anos, após a cirurgia bariátrica. Os demais apresentavam menor reganho de peso ou menor tempo de cirurgia de bypass e o peso ainda pode não ter se estabilizado, de forma a realmente caracterizar reganho de peso. A seleção foi realizada por meio do controle de assiduidade às consultas e o con- 


\section{INERAC̄OOEM ETSPICOLOGIA}

tato inicial foi realizado por telefone. Foram entrevistados cinco homens e cinco mulheres. Três eram funcionários públicos, dois eram empresários, um era fisioterapeuta, um dentista, um advogado, um administrador de empresa e um trabalhava no ramo de hotelaria.

\section{INSTRUMENTOS}

Foi utilizado um roteiro de entrevista semiestruturada constituído por 64 perguntas sobre:

- Dados sociodemográficos: faixa etária, renda, escolaridade e profissão.

- Dados clínicos: IMC antes e após a cirurgia, porcentagem de reaquisição de peso até a data da entrevista, comorbidades, demandas de cirurgia.

- Hábitos alimentares anteriores e posteriores à cirurgia bariátrica: quantidade ingerida de alimento, grupos alimentares de preferência (carboidratos, proteínas, gorduras, gorduras saturadas e trans., açúcares etc.), alterações no paladar, velocidade da ingestão alimentar, rituais à mesa (se existem, se comem em ambiente apropriado), aspectos que colaboraram para reaquisição de peso.

- Mudanças no estilo de vida: mudanças na interação social, profissional, educacional ou relacional com as mudanças proporcionadas pela cirurgia; mudanças na apresentação pessoal e na rotina diária.

- Mudanças comportamentais: mudanças de humor e nas relações interpessoais após o procedimento cirúrgico.

- Imagem corporal e autoestima: memória do corpo obeso, reações sociais ao corpo emagrecido, reações sociais ao corpo após reganho de peso, adaptação do vestuário após emagrecimento veloz e maciço, noção de flacidez e percepção da necessidade de cirurgia plástica.

- Preconceitos vivenciados com a opção pela cirurgia bariátrica e com o reganho de peso: críticas e reações do grupo perante a obesidade, perda de peso e reganho de peso, nova forma corporal e novos hábitos alimentares.

Essas categorias foram pré-definidas de acordo com a literatura científica que aborda a temática do reganho de peso e por estarem relacionadas aos objetivos da pesquisa.

\section{PROCEDIMENTO}

Após a seleção e convite dos participantes, foi realizada uma entrevista individual em uma sala privativa na clínica. $\mathrm{Na}$ ocasião da entrevista, cada participante recebeu o termo de consentimento livre e esclarecido (TCLE), que foi devidamente assinado e datado por cada participante. As entrevistas duraram, em média, uma hora e quarenta e cinco minutos.
Nenhum dos participantes manifestou oposição à gravação da entrevista. As entrevistas foram transcritas e os dados obtidos foram submetidos à análise de conteúdo.

\section{ANÁLISE DE DADOS}

A Análise de Conteúdo constitui um método de investigação utilizado em pesquisas qualitativas que, segundo Rocha e Deusdará (2005), objetivaram alcançar um sentido profundo ou estável, conferido pelo pesquisador no próprio ato de produção do texto. Segundo Franco (2008), a criação de categorias é característica pontual da Análise de Conteúdo. Foram estabelecidas algumas categorias à priori, com um roteiro de entrevistas semiestruturado. As respostas fornecidas pelos entrevistados foram agrupadas de acordo com as perguntas realizadas. Os diversos conteúdos presentes no discurso dos participantes foram descritos de forma a analisar as diferentes experiências subjetivas referentes às categorias estudadas.

\section{RESULTADOS}

Das 10 pessoas que foram submetidas à entrevista semiestruturada, foi possível observar a heterogeneidade nas profissões, idades e demandas da cirurgia bariátrica. A idade média dos entrevistados foi de 49,6 anos (desvio padrão = 12,62 ) e variou entre 32 e 69 anos. 0 tempo médio desde a realização da cirurgia foi de 8,7 anos (desvio padrão $=4,32$ ), variando entre 4 anos e 16 anos. 0 maior IMC (índice de massa corporal) foi de $57,61 \mathrm{~kg} / \mathrm{m} 2$ e o menor de $35,98 \mathrm{~kg} / \mathrm{m} 2$. A maior redução de peso foi de $47 \%$ do peso total do indivíduo e a maior recuperação ficou em $23,7 \%$ do montante perdido, na mesma pessoa. Foram relatadas várias doenças presentes antes da cirurgia, relacionadas à obesidade mórbida: pressão alta, colesterol e triglicerídeos altos, problema na coluna, dores no joelho, gordura no fígado (esteatose hepática), diverticulite, pólipos estomacais, isquemia cardíaca, isquemia cerebral, fadiga, insônia.

A partir da análise do conteúdo das entrevistas observouse que medo e apreensão de reganho de peso estavam presentes em todos os participantes da pesquisa. Esses afetos negativos reforçam a ideia de que o estigma social e moral sofrido pelo obeso mórbido (grau III) são marcas psíquicas mediadas pela vivência social e passam a constituir stress após um trauma. Dos 10 participantes, nove apresentaram no discurso a palavra "medo" e um a palavra "apreensão" do reganho de peso, constituindo esse elemento discursivo comum a todos.

"Tenho medo. Morro de medo. Entrei na menopausa e parei de fumar. Meu medo de engordar é tão grande... eu 


\section{HE INTERACÃO EM LFT PSICOLOGIA}

não posso voltar a ser aquela gorda que eu era."

"Eu tenho medo de voltar tudo que eu tinha... daí eu fico me cuidando... foi muito sofrimento, né?! "

"Existe... ah existe o medo de engordar sim! Quando começo a comer sem sentir o gosto do que eu to comendo... eu sei que to muito ansiosa, então tá na hora de pará".

"Tenho medo! To com medo muito grande! ...Eu já lutei tanto, sofri tanto pra ficar magro, né?! E agora de uma hora pra outra, não sei o porquê to recuperando peso."

Todos descreveram a memória da obesidade como algo impresso no corpo, isto é, uma experiência vivida concretamente, que deixou marcas psíquicas negativas e marcas físicas que não podem ser negadas: flacidez, estrias, registro de privações alimentares, dores cirúrgicas, cicatrizes de plásticas em maior ou menor grau. Observaram-se relatos sobre: dificuldades em comprar vestimentas; dificuldade no preparo de pequenas quantidades de alimentos; a experiência da discriminação; a obesidade como limitação da vida no seu curso natural; o fantasma do reganho de peso; a dificuldade de pensar em comida sem voracidade ("cabeça de magro"); e o retorno de memórias que ressurgem em flashes.

A dificuldade em comprar roupas era uma queixa geral dos entrevistados já no pré-operatório e intimamente ligada à condição da obesidade e demais excluídos (anões, excessivamente altos etc). Embora existissem lojas especializadas em tamanhos plus size, as roupas desses estabelecimentos foram descritas como "Roupas de velha, bege, em forma de saco!"; "Até parece que gordo não tem sexo, só tem lingerie bege!". Roupas da moda, vendidas em lojas de departamentos e a preços acessíveis pertenciam a moldes em que o tamanho extragrande vestia o médio, segundo os pacientes bariátricos.

Para os pacientes jovens, a obesidade mórbida trazia limites físicos que antecipam a sensação do avanço da idade. A pessoa ficava ofegante, com dificuldades no sono, limitação nos movimentos e, por vezes, na auto higiene. Eles relataram que passavam a não ter disposição para fazer exercícios e mesmo os que se sentiam mais animados ficaram mais propensos às distensões musculares e lesões. A experiência do emagrecimento promovido pela cirurgia bariátrica devolveu o corpo jovem para a cabeça que funcionava com desejos de pouca idade.

Ainda que a fome seja reduzida pela própria técnica cirúrgica (mecanismo de redução da grelina, hormônio da fome), o apetite não reduz em um primeiro momento e muitos pacientes passaram a ter dificuldade em adequar o modo de preparar a alimentação, ou mesmo de se servir após dois a três meses de cirurgia, quando estavam aptos para a vida alimen- tar normal. Faziam seus pratos com quantidades maiores do que eram capazes de comer, motivados pelo desejo do olhar e não pela fome gástrica.

"As vezes eu tô mais ansiosa. E eu como um pouco a mais de doce. Hoje eu pus o meu olho... tá de gorda de novo, entende. Eu já percebi isso. Eu pus um monte de comida no meu prato, quando eu olhei assim. Credo! Opa! (mão na barriga) Sabe, comi demais!"

0 reganho de peso era um "fantasma" que perseguia essas pessoas que lutaram por inúmeras vezes para perder peso. Pelas experiências anteriores, cada tentativa foi seguida de curto período de manutenção dos resultados e o retorno rápido do peso perdido, seguido de um peso adicional indesejado. Um dos entrevistados chegou a desenvolver anorexia restritiva pós-bariátrica por causa do pensamento obsessivo de que a cirurgia, para ele, não daria certo. Outro entrevistado ainda induzia vômito quando se sentia cheio (mecanismo intencional da cirurgia restritiva). Seu pensamento automático era o de que comeu desnecessariamente, e essa sensação o relembrava os tempos da obesidade e falta de controle sobre o peso.

“Sim. Depois de 11 anos eu sou um gordo, ainda, de cabeça!"

"Algumas coisas que eu vou comprar, assim, se eu compro muito... exagerada... comida principalmente... comida, sabe... as vezes eu vou fazer.... eu não consigo fazer pouco... eu faço muito, entende."

“Ficou... ficou muito forte e agora pouco tempo foi como um fantasma me assombrando por causa do reganho de peso, então eu fiquei muito preocupado. Eu fiquei assim quando cheguei a beirar perto dos 100 quilos. Ali me deu um desespero. Fiquei muito preocupado, porque voltou aquela imagem de obesidade na minha cabeça"

0 modo de pensar a comida conduz à relação específica de cada pessoa com os alimentos desenvolvida na interação pessoa, família e cultura. A comida, em geral, vista como satisfação oral, apareceu em respostas sociais referentes a situações prazerosas, fartura, memória condicionada referente às experiências individuais. É frequente a indignação frente à pequena quantidade ingerida pelo operado bariátrico, inadequadamente confundida com mal-estar físico, não apreciação do prato ou desprezo a quem oferece o alimento. A cultura alimentar ainda revela que dar alimento e receber alimento são comportamentos cercados de significados de acolhimento, aceitação, agrado e afeto.

“Muitas pessoas. Essa é uma dificuldade que eu encontro, acho assim: - Come mais um pouquinho! Você comeu tão pouco. Então você não gostou da minha comida!" 


\section{H. INTERACÃO EM LFT PSICOLOGIA}

"As pessoas estranham tanto quanto a gente. E depois acham que você não gostou da comida. Mas eu já vou falando que sou operada!"

"Ah sim, principalmente na família né, porque a família fica... fica naquela assim... é a mãe olha... assim e fala... puxa... você comeu tão pouco né. Coma mais um pouco... olha... eu fiz isso pra você"

Algumas memórias relacionadas à obesidade foram citadas como flashes que ressurgem como sensações corporais ou pensamentos ligados ao constrangimento do passado: sensação da roupa pegando no corpo; ser olhado quando entra em um ambiente cheio; não usar shorts numa praia; o controle familiar em torno do tema comer.

"Ah tá! Eu me lembro sempre dos incômodos. Dos problemas de entrar num avião e pedir mais um cinto pra me arrumar. Isso aí não sai da cabeça da gente. Isso é até bom, né? Isso é até bom porque daí você recicla pra não voltar [...] Eu acho! Eu não posso esquecer da minha [...] Porque foi a maior parte da minha vida Eu to com 69 e maior parte dos 69 eu fui obeso."

Os participantes relataram a importância do feedback social sobre o reganho do peso. A sinalização teve a função de espelho, que os fizeram raciocinar sobre a imagem corporal e as suas atitudes alimentares, mas também comprovou a hipótese de que o obeso era, de fato, objeto de observação social constante.

“É, as pessoas avisam... - Olha você tá engordando de novo! E eles tem razão, né?!"

"Todo mundo, todo mundo dizia: O que adiantou fazer a cirurgia bariátrica se tá gorda de novo? É!! Passou tanto sacrifício, fez tanta coisa pra ficar toda balofa aí de novo!"

"Ah, você precisa maneirar, porque você tá engordando! Ah, você engordou! Tem essa coisa de vigilância."

"Olha, você vai voltar ao normal, hein?! Vai voltar de novo! Você já tá com 90 ... daqui a pouco tá com 100! Mas eu mesmo me preocupo!"

A memória de ter sido obeso foi considerada uma marca psicológica traumática por todos os participantes. A experiência da discriminação social, das limitações físicas, da falta de acolhimento grupal e das fases existenciais não autorizadas socialmente, deixaram lembranças que não se apagaram. O obeso foi condenado como culpado pelo seu mal, diferentemente de qualquer outra doença crônica, do qual o sujeito era vítima e suscitava compadecimento e ajuda. Foi sublinhada a dificuldade de que se venha a considerar a obesidade como uma etapa passada, dada à proximidade do pro- blema no tempo recente.

Como categoria à posteriori, surgiu a contradição entre fazer uma cirurgia para perder peso e o medo da imagem excessivamente magra. Oito dos 10 entrevistados apresentaram reganho de peso para chegar a uma imagem condizente com sua identidade imagética, isto é, uma imagem que se encaixasse com a figura interna imaginária que carregavam de seu próprio corpo. Mas, nessa tentativa, passaram do montante necessário. Essas questões pareciam estarem permeadas pelos conceitos de "flacidez" e pela "aparência de doente" criticada socialmente.

“Depois eu fiquei bem alegre, eu fiquei magra, todo mundo... só que daí eu emagreci demais e envelheci demais também... Eu fiquei realmente abatida."

"Eu ficava ansiosa pra me pesar, né, porque assim mesmo, é contraditório... mesmo quando você olha e diz: nossa! Parece que não sou eu... to muito magra... você quer perder mais."

Dois participantes mantiveram seu estilo de roupa e modo de apresentação igual às de antes da cirurgia. Os oito restantes disseram ter certa dificuldade em comprar roupas e que desenvolverem tentativas de encaixar seu esquema corporal num padrão de vestimenta mais jovem.

"você tá magra... você usa roupa de magra... não vou usar aqueles sacos... então comprei... dei todas as minhas roupas, mas dei tudo... tudo... tudo... comprei calça jeans cintura baixa... tudo que eu queria usar, sabe... passou... foi aquela fase... porque assim... eu acho assim que a gente fica numa fase de euforia. A gente quer tudo... tudo...tudo... daí a calça baixa... não sei o quê... top... e depois nada daquilo é importante"

Dos dez entrevistados, dois afirmaram que suas experiências bariátricas acabaram em divórcio devido à falta de estrutura do companheiro em conviver com alguém com a autoestima mais elevada, isto é, com uso de mecanismos psíquicos mais maduros e menos complementares nas relações doentias de poder. Duas famílias ficaram temerosas quanto ao possível desenvolvimento de anorexia nervosa após o emagrecimento de pessoas que foram obesas desde a infância.

A opinião sobre a cirurgia plástica não necessariamente coincidiu com o fato de ter se submetido ao procedimento estético. Muitos se mostraram favoráveis à cirurgia plástica, mas tiveram conflitos em relação ao procedimento estético. Abaixo, relatos que demonstram ambiguidades em relação à segunda chance de vida dada pela bariátrica e risco da cirurgia plástica.

“Não adianta você só fazer a cirurgia. Você vai emagre- 


\section{INTERACÃO EM LFT PSICOLOGIA}

cer... está... mais... é... e toda aquela pele que tá sobrando, sabe. Você não consegue se visualizar porque você tem que trabalhar também depois... é o espaço corporal."

"quando eu penso na plástica eu sempre penso que é uma coisa meio supérflua, assim, sabe? Daí eu penso: Ai será que eu vou, mas eu vou me submeter a isso e sendo que não é uma necessidade! Eu não vou morrer se eu não fizer. Deus já foi tão bom comigo, né?! Me fez todas as cirurgias, está tudo certo, estou feliz, estou bem, Aí eu fico pensando se não é um excesso, sabe?. Não quero ficar com essa pele na barriga, sabe?! Seio.."

"Vou fazer, fazer uma lipo abdominal, vou cortar aqui em baixo, tirar o excedente, levantar isso aqui que tá tudo caindo lá pra baixo. 0 tecido tá pesado de gordura, e quero tirar as duas mamas, assim... Quero tirar!! Tenho vergonha dos meus peitos! Eu tenho vergonha. Então, por exemplo, eu não vou à praia."

Há um longo trajeto da obesidade até o corpo idealizado e mesmo após as cirurgias plásticas não existem garantias do acesso à imagem corporal que foi idealizada no pré-cirúrgico. Observa-se que também existia uma adaptação ao novo corpo, uma insatisfação com a flacidez, que afetava a imagem corporal.

"Eu fiquei muito chupada, assim, fiquei muito feia.... Caiu tudo, assim, depois eu acho assim.... quando você é nova... dá pra bota no lugar, mas eu já tinha 40 anos. Não volta. Caiu tudo aqui [mão nas nádegas]. Eu me sinto muito bem hoje. Me sinto muito bem mesmo. Claro que eu se que eu não sou nenhuma miss, que eu tenho 50 anos. Acho que tem que ter essa noção, né."

\section{DISCUSSÃO}

O estigma e o preconceito englobam ações e atitudes de não aceitação aos padrões que ameaçam às normas de um grupo ou sociedade. As pessoas com obesidade relatam com frequência que são discriminados (Spahlholz, Baer, Könic, Riedel-Heller \& Luck-Sikorski, 2015). Todos os padrões que sejam julgados como diferentes e ameaçadores para um grupo tendem a ser banidos e deixados à margem. A falta de identidade com o grupo promove no "diferente" um afastamento enquanto os iguais tendem a se aglomerar por afinidade e sensação de acolhimento e compreensão. A diferença e a semelhança entre os pares tendem a afetar as nossas relações interpessoais e as atividades globais em longo prazo. A amostra estudada evidenciou o importante papel atribuído à aprovação ou desaprovação do grupo social frente à imagem corporal do operado bariátrico. A sinalização do reganho de peso como alerta de um possível retorno à exclusão social foi bem recebida, uma vez que foi interpretada como afeto positivo e cuidado. $\mathrm{O}$ estigma se manifestou de várias formas. $\mathrm{Na}$ forma verbal foi externalizado em provocações orais que expõe o difente ao ridículo. Aparece em forma de insultos, formação de estereótipos, nomes depreciativos ou linguagem pejorativa. 0 estigma físico se manifestou em forma de brincadeiras estúpidas, qualificadas hoje no critério de bullying, como tocar agressivamente, agarrar, ou manifestar outros comportamentos desagradáveis.

Os benefícios com um corpo magro e ágil, com fácil locomoção, qualidade positiva de sono, oxigenação, circulação, sexualidade funcional e positiva, dão indícios do medo do que o reganho de peso representa para $100 \%$ dos entrevistados e explicam as discriminações em torno do obeso. Rusch e Andris (2007) descreveram a força do estigma em relação à obesidade por meio de um estudo que mostrou que pacientes com início da obesidade na infancia ou pré-adolescência apresentaram menor satisfação com a imagem corporal depois de perder peso, do que pacientes com obesidade tardia. Eles compararam dois padrões de recuperação de peso intencional após a cirurgia bariátrica, ambos ligados à imagem corporal. Um deles seria o desgosto com a pele pendurada e a flacidez. 0 outro padrão descrito é o emagrecimento excessivo, com o aparecimento dos ossos das costelas e a desproporção ao tronco. 0 relato dos entrevistados também evidenciou situações de preconceito vivenciado em função do emagrecimento repentino e da dificuldade em lidar com os efeitos secundários póscirúrgicos, como lidar com o corpo flácido e o impacto na autoimagem. Como a cirurgia plástica não era, até recentemente, financiada por convênios, encher um pouco a pele no primeiro caso, ou ganhar peso, no segundo, seriam modos de reestruturar a imagem corporal. No Brasil, os convênios médicos discutem o custeio de cirurgias estéticas em cirurgias bariátricas. É necessário um trâmite legal para que o paciente comprove que a cirurgia plástica é reparadora. Mais estudos nesse sentido teriam de ser desenvolvidos. No entanto, o que se sabe é que quanto mais tarde é realizado o procedimento estético, maior é a acomodação com a imagem corporal, mesmo que haja insatisfação com essa imagem (Cash, 2008; Sperry, Thompson, Sarwer \& Cash, 2009). Similarmente, observou-se que alguns pacientes optam por não fazerem a cirurgia reparadora, mesmo insatisfeitos com seu próprio corpo, mas demonstraram uma certa acomodação à sua nova imagem corporal.

No presente estudo, encontramos o relato de grupos e familiares que exerceram função crítica sobre a nova imagem corporal do paciente. Uns aconselhando o ganho de peso, outros criticando a falta de manutenção dos resultados. Mas, apesar da recuperação de certa quantidade de peso, o medo de voltar a engordar e do sofrimento ligado à experiência de ter sido obeso ficaram como memória e ameaça. Observa-se 
que existe o temor, desde o pré-operatório, de que o emagrecimento não seja autolimitado e mais, de que a imagem da magreza seja associada à fraqueza e doença. Rusch e Andris (2007) chegaram às mesmas conclusões que o presente estudo. A intenção de modelar o corpo com uma pequena reaquisição de peso passou do ponto desejado em sua amostra e avançou para números mais altos.

Mitchell et al. (2001) realizaram um estudo de seguimento com um grupo de 100 pacientes bariátricos em que todos inicialmente relataram benefícios em termos de saúde física e qualidade de vida. No entanto, $68 \%$ permaneceram com vômitos depois de decorrido tempo de cirurgia bariátrica e $42,7 \%$ permaneceram com "entaladas" (dificuldade para engolir alimento) devido a dificuldades com o ritmo alimentar. Oito pacientes faleceram. Nesse mesmo estudo, o medo de voltar a engordar apareceu em $89,7 \%$ do total acompanhado e $98,7 \%$ insatisfeitos com a imagem corporal. Similarmente, observou-se entre os entrevistados que o medo de reganho de peso e a insatisfação com os resultados da cirurgia são muito frequentes.

Sarwer et al. (2007) relataram em estudo que envolveu a cirurgia plástica na satisfação com a imagem corporal, que até 2008 cinquenta e cinco mil indivíduos tinham se submetido à técnica de contorno corporal depois da cirurgia bariátrica. Teoricamente, a insatisfação com a imagem corporal deveria motivar a busca das cirurgias plásticas, mas estudos pregressos (Cash, 2008; Sperry et al., 2009) demonstraram que essa insatisfação procrastina a busca pela correção estética. Um dos motivos é a falta de cobertura dos convênios. Mas de acordo com o estudo aqui presente, foi constatada a presença de um grau variante de temor em submeter-se a outro risco cirúrgico, que engloba o período pós-operatório e suas particularidades.

Thompson (2001) afirma que o índice de divórcio é alto, assim como Orzech (2005). Muitos casamentos de pessoas obesas têm como base a estima rebaixada e a crença de que devem se acomodar ao primeiro parceiro que as aceite. $\mathrm{Na}$ medida em que passam a experimentar a possibilidade de optar, ocorre instabilidade nas relações afetivas. Com o aumento da autoestima e consciência da atratividade física muitos repensam a permanência em relações insatisfatórias. De acordo com o estudo aqui apresentado, foi possível perceber a dificuldade de conviver com a pessoa mais magra e independente, antes submissa em uma relação de poder, como observado anteriormente na citação de Orzech (2005). Mas, é inegável que em muitas entrevistas pré-operatórias, contextos conjugais desastrosos aparecem, mesmo que de forma dissimulada e o parceiro obeso busca na cirurgia uma maneira de alterar seu padrão existencial. Assim, parece que alguns divórcios e separações já estavam implícitos no processo de transformação do corpo e da vida dessas pessoas.

A descrição dos conflitos nas compras de novas roupas foram encontradas em livros e artigos de operadas bariátricas que trabalham no aconselhamento de antigos e futuros pacientes. Thompson (2001) e McNelly (2008) descrevem resultados semelhantes ao presente estudo, em relação às compras de novas roupas. Existe a tendência de solicitar em lojas ou pegar tamanhos maiores do que os que realmente servem. Em geral o corpo real está menor que a roupa escoIhida, do mesmo modo que o prato servido está mais cheio que a capacidade gástrica pós-operatória. A sensação de rejuvenescimento que acompanha a perda de peso faz com que uma parcela de pacientes vá à busca de roupas mais modernas e juvenis. Para alguns existe a insegurança quanto ao balanço entre a crítica social e a autocrítica.

\section{CONCLUSÃO}

O estudo realizado possibilitou, por meio de análise das entrevistas de pacientes bariátricos que recuperaram peso, entrar em contato com a percepção corporal desses indivíduos. Nesta análise foi possível verificar o intervalo existente entre o emagrecimento no corpo e a construção da imagem corporal, principalmente para aqueles que nunca tiveram a experiência de serem magros. Para aqueles que já experimentaram a magreza, a cirurgia teve papel de resgate de uma imagem já existente, porém se faz necessário um estudo psicométrico mais aprofundado, com maior amostragem de pacientes, para avaliar a magnitude da satisfação dos resultados nesses dois grupos. 0 período de emagrecimento excessivo foi vivido com ambiguidade: prazer associado à consciência de necessidade do reganho parcial de peso. A possibilidade de recuperar a condição de magro após o reganho de peso foi vivida com satisfação, principalmente em seu contexto social, em especial pela experiência inédita de ouvir o grupo insistir para que coma mais e que engorde. A perda do controle na reaquisição do peso se tornou um problema para os operados. 0 aumento gradual do peso acionou o medo de voltar a engordar, experiência já vivida múltiplas vezes pela maioria dos entrevistados. A sinalização social do reganho de peso passou a ser de grande importância e agiu como freio que teve início na avaliação do grupo. 0 medo do reganho de peso, na grande maioria das vezes, esteve ligado ao estigma social, às experiências prévias de rejeição e vergonha, ao sentimento de inadequação que fizeram com que o próprio sujeito, como parte da sociedade, rejeitasse a si próprio.

As cirurgias plásticas aplicadas à cirurgia bariátrica foram buscadas no ideal da reconstrução corporal. Foram avaliadas como complementação e parte do processo bariátrico. Ainda 


\section{H NTERAC̄OA EM ET PSICOLOGIA}

existem dificuldades quanto à equação entre flacidez e cicatriz. A busca da imagem sem marcas ou memórias implica em novas emoções de conteúdo ambíguo, ciúmes do parceiro, que impedem o embelezamento do operado e levam ao constrangimento frente às cicatrizes das plásticas. Esses elementos do âmbito conjugal necessitam também de maiores pesquisas, de forma a investigar o seu impacto na autoimagem e na manutenção ou reganho de peso. Apesar de se tratar de um estudo qualitativo, que não pretende generalizar seus resultados para todas as pessoas que tiveram reganho de peso após a cirurgia bariátrica, os dados evidenciam a necessidade de aprofundar os estudos sobre a reconstrução da imagem corporal após a cirurgia bariátrica, o seu impacto na autoestima e autoconceito da pessoa. Também foi evidenciada a necessidade de aprofundar os estudos sobre a influência das relações interpessoais, do contexto social e grupal (que constroem o ideal de beleza) na construção da autoimagem corporal.

\section{CONTRIBUIÇÃO DE CADA AUTOR}

S.D.M. e M.C.A. contribuíram para a conceitualização e metodologia da pesquisa; S.D.M. foi responsável pela investigação e redação inicial do artigo (rascunho) e M.C.A. fez a redação final (revisão e edição).

\section{DECLARAÇÃO DE CONFLITOS DE INTERESSES}

Os autores declaram que não há conflitos de interesses no presente artigo.

\section{REFERÊNCIAS}

Agliata, D., \& Tantleff-Dunn, S. (2004). The impact of media exposure on males' body image. Journal of Social and Cli$\begin{array}{lll}\text { nical } & \text { Psychology, 23(1), } & \text { 7-22. }\end{array}$ http://dx.doi.org/10.1521/jscp.23.1.7.26988

Berti, L.V., Campos, J., Ramos, A., Rossi, M., Szego, T., \& Cohen, R. (2015). Posição da SBCBM - nomenclatura e definições para os resultados em cirurgia bariátrica e metabólica. ABCD Arquivos Brasileiros de Cirurgia Digestiva, 28(supl.1), 2-2.

Cash, T. E, Cash, D. W., \& Butters, J. W. (1983). "Mirror, mirror, on the wall...?": Contrast effects and self-evaluations of physical attractiveness. Personality and Social Psychology Bulletin, 9, 351-358.

Cash, F. T. (2003). Body image: Past, present, and future. Editorial Body Image, 1(1), 1-5. http://dx.doi.org/10.1016/S1740-1445(03)00011-1

Cash, F. T. (2008) The body image workbook. USA, Oakland: New Harbinger Publications.
Colles, S. L., Dixon, J. B., \& O’Brien, P. E. (2008). Grazing and loss of control related to eating: two high-risk factors following bariatric surgery. Obesity (Silver Spring), 16(3), 615-622. http://dx.doi.org/10.1038/oby.2007.101

Franco, M. L. P. B. (2008). Análise de Conteúdo. Brasília: Liber Livro.

Karmali, S., Brar, B., Shi, X., Sharma, A. M., de Gara, C., \& Birch, D. W. (2013). Weight recidivism post-bariatric surgery: a systematic review. Obesity Surgery, 23(11), 1922-1933. http://dx.doi.org/10.1007/s11695-013-1070-4

Magro, D. (2006). Uma palavra do nutricionista para o psicólogo que trabalha com paciente submetido ao tratamento cirúrgico da obesidade. Em Franques, A. \& Loli, S. Contribuições da Psicologia na Cirurgia da Obesidade. São Paulo: Vetor Psico-Pedagógica.

McNally, R (2008). Gastric Bypass Surgery. The Psychological Journey. USA, Bloomington: Author House.

Mitchell J. E., Lancaster K. L., Burgard M. A., Howell L. M., Krahn D. D., Crosby R. D., Wonderlich S. A., \& Gosnell B. A. (2001). Long-term follow-up of patients' status after gastric bypass. Obesity Surgery, 11(4), 464-8. http://dx.doi.org/10.1381/096089201321209341

Organização das Nações Unidas no Brasil (2017). Aumentam sobrepeso e obesidade no Brasil, aponta relatório de FAO e OPAS. Disponível em: https://nacoesunidas.org/aumentam-sobrepeso-e-obesidade-no-brasil-aponta-relatorio-defao-e-opas/ Acesso em: 25/01/2017.

Orzech, D. (2005). Counseling bariatric surgery patients. Social Work Today, 5(6), 24.

Rocha, D. \& Deusdará,B. (2005). Análise de conteúdo e análise do discurso: Aproximações e afastamentos na (re)construção de uma trajetória. Alea: Estudos Neolatinos, 7(2), 305-322. http://dx.doi.org/10.1590/S1517106X2005000200010

Rosen, J. C. (1990). Body image disturbances in eating disorders. Em T. Cash, \& T. Pruzinsky (Eds.), Body images: Development, deviance, and change (pp. 190-214). New York: Guilford Press.

Rosen, J. C., \& James, C. (2001). Improving body image in obesity. Em J. K. Thompson (Ed.), Body image, eating disorders, and obesity: An integrative guide for assessment and treatment (pp. 425-440). Washington, DC, USA: American Psychological Association, 425-440. Retirado de http://psycnet.apa.org/index.cfm?fa=buy.optionToBuy\&id=2004-14112-017

Rusch, M. D., \& Andris, D. (2007). Maladaptive eating patterns after weight-loss surgery. Nutricional in Clinical Practice, 22(1), 41-49. http://dx.doi.org/10.1177/011542650702200141

Sarwer, D. B., Wadden, T. A., Moore, R. H., Eisenberg, M. H., Raper, S. E., \& Williams, N. N. (2010). Changes in quality of life and body image after gastric bypass surgery. Surgery 


\section{MI* INTERACÃO EM LF PSICOLOGIA}

for Obesity and Related Diseases, 6(6), 608-614. http://dx.doi.org/10.1016/j.soard.2010.07.015

Faln, J. (2012, Novembro 16) Body image researcher David Sarwer debunks Hollywood myths. [Post do blog Huffpost] Retirado de http://www.huffingtonpost.com/jeanfain-licsw-msw/body-image_b_2133442.html

Sociedade Brasileira de Cirurgia Bariátrica e Metabólica, SBCBM (2017) Consenso bariátrico brasileiro. Disponível em: http://www.sbcb.org.br/imagens/pdf/consenso_baraitrico_brasileiro.pdf

Souza, M. R. R., Oliveira, J. F., Nascimento, E. R., \& Carvalho, E. S. S. (2013). Droga de corpo! Imagens e representações do corpo feminino em revistas brasileiras. Revista Gaúcha de Enfermagem, 34(2), 62-69. https://dx.doi.org/10.1590/S1983-14472013000200008

Spahlholz, J., Baer, N., Könic, H. H., Riedel-Heller, S. G., \& LuckSikorski, C. (2015). Obesity and discrimination - A systematic review and meta-analysis of observational studies. Obesity reviews, 17(1), 43-55 https://dx.doi.org/10.1037/hea0000426

Sperry, S., Thompson, J. K., Sarwer, D. B., \& Cash. T. F. (2009). Cosmetic surgery reality TV viewership: Relations with cosmetic surgery attitudes, body image, and disordered eating. Annals of Plastic Surgery, 62(1), 7-11. https://dx.doi.org/10.1097/SAP.0b013e31817e2cb8
Steffen, K. J., Sarwer, D. B. Thompson, J. K., Mueller, A., Baker A. W., \& Mitchell, J. E. (2012). Predictors of satisfaction with excess skin and desire for body contouring after bariatric surgery. Surgery for Obesity and Related Diseases, 8(1), 92-97. http://dx.doi.org/10.1016/j.soard.2011.06.022

Stice, E., Schupak-Neuberg, E., Shaw, H. E., \& Stein R. I. (1994). Relation of media exposure to eating disorder symptomatology: An examination of mediating mechanisms. Journal of Abnormal Psychology, 103(4), 836-840. http://dx.doi.org/10.1037/0021-843X.103.4.836

Thompsom, B. (2001). Weight Loss Surgery. Finding the thin person hiding inside you! USA, Tarentum: Word association.
Recebido em: 05/08/2016 Primeira decisão editorial em: 03/03/2017 Aceito em: 13/06/2017 